\section{Successful endoscopic therapy of intrahepatic bile leaks following hepatic gunshot injury: Report of two cases}

There are virtually no reports of gunshot wounds causing intrahepatic bile duct leaks, although extrahepatic bile duct injuries following hepatic gunshot wounds are common [1-4]. We present two cases of successful endoscopic management in patients with delayed presentation of intrahepatic bile leaks resulting from hepatic gunshot injuries.

Patient 1. A 28-year-old man sustained a gunshot wound to the mid-epigastrum. Laparotomy revealed through-andthrough liver injury, treated surgically. The patient did well until postoperative day 11 when bilious fluid was noted to exit the wound. Computed tomography (CT) scan revealed a perihepatic fluid collection and a biliary-cutaneous fistula.

Endoscopic retrograde cholangiopancreatography (ERCP) revealed a large bile leakage from a left intrahepatic bile duct (Figure 1). A biliary sphincterotomy was performed and a $10 \mathrm{Fr} \times 7 \mathrm{~cm}$ plastic biliary stent was placed. ERCP at 6 weeks later showed complete closure of the bile duct with a normal cholangiogram (Figure 2).

Patient 2. A 25-year-old man sustained a gunshot wound to the right upper quadrant with a penetrating liver injury and underwent operative repair.

On postoperative day 18 , the patient developed fever and pain, and was found on CT scan to have a perihepatic fluid collection. ERCP demonstrated a small left intrahepatic bile duct leak. A biliary sphincterotomy was performed and a $10 \mathrm{Fr} \times 7 \mathrm{~cm}$ biliary stent was placed. At 4 weeks later, ERCP showed resolution of the leak and no evidence of stricture.

Conclusion. Although poorly described in the literature, intrahepatic bile leaks can occur as a result of hepatic gunshot wounds, and their manifestation may be delayed compared with leaks induced by laparoscopic cholecystectomy or by extrahepatic injury caused by gunshot wounds [5]. This may be due to early tamponade

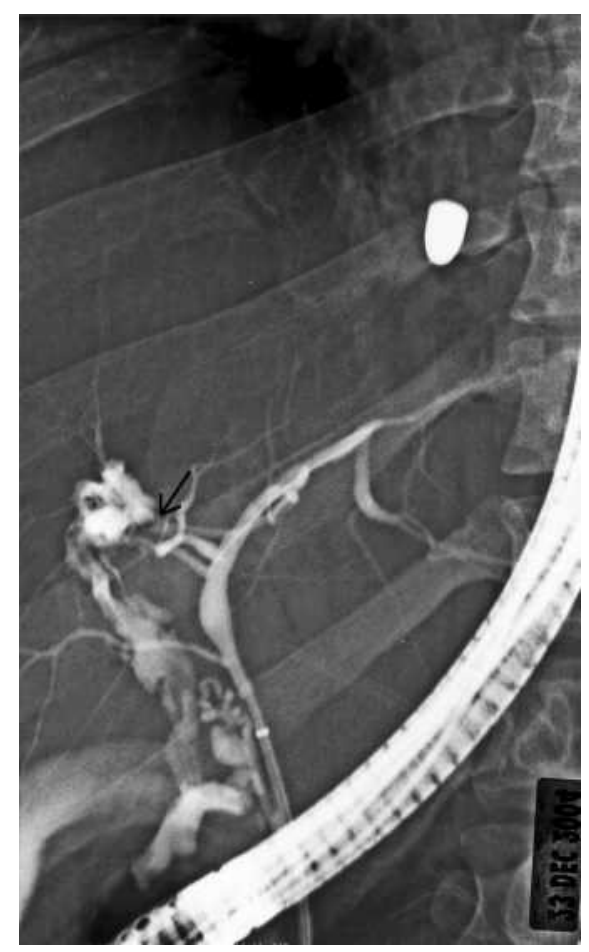

Figure 1 Initial cholangiogram from patient 1 , demonstrating a leak from a small rightward intrahepatic branch from the left hepatic duct (arrow). Note the bullet visible at the top of the image.

of these leaks secondary to edema. As swelling abates, active leakage can be seen with associated fluid collections. These intrahepatic injuries respond to endoscopic therapy.

\section{Endoscopy_UCTN_Code_TTT_1AR_2AG}

\section{P. Spinn, D. G. Adler}

Division of Gastroenterology and Hepatology, University of Texas-Houston Medical School, Houston, Texas, USA.

\section{References}

\footnotetext{
${ }^{1}$ De Luca N, Bourke M, Williams S. Endoscopic treatment of bile leak caused by gunshot injury. Gastrointest Endosc 2001; 53: 778

2 Degiannis E, Khelif K, Leandros Eet al. Gunshot injuries of the extrahepatic biliary ducts. Eur J Surg $2001 ; 167: 618-621$

${ }^{3}$ Feliciano DV, Bitondo CG, Burch JMet al. Management of traumatic injuries to the extrahepatic biliary ducts. Am J Surg 1985; 150: 705-709
}
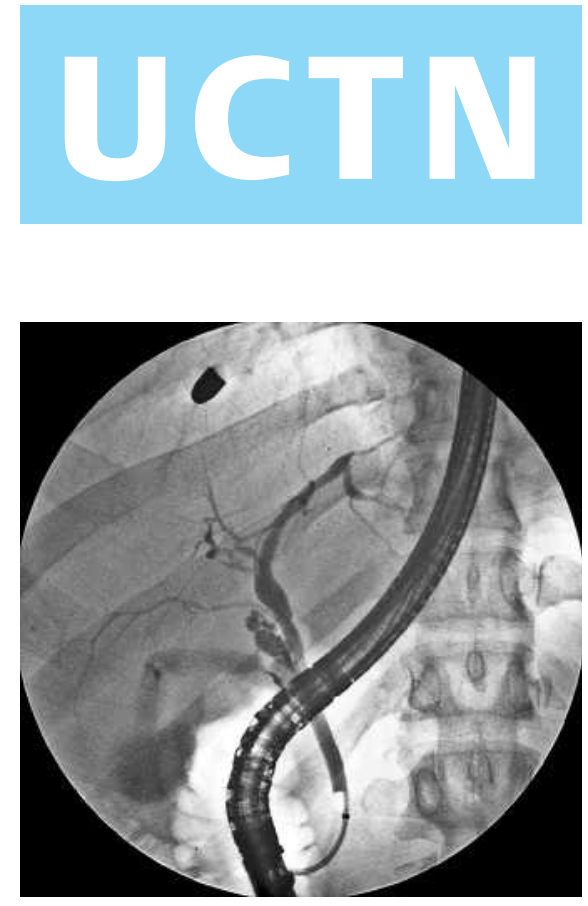

Figure 2 Cholangiogram obtained from patient 1, at 6 weeks later, showing closure of the leak and normal biliary anatomy.

\footnotetext{
${ }^{4}$ Chmatal P, Zavoral M, Fencl Pet al. Gunshot liver trauma with disruption of the right hepatic duct managed by surgery, radiology, and endoscopy: a case report. Int Surg 2004; 89: $67-71$

${ }^{5}$ Ryan M, Geenen J, Lehman Get al. Endoscopic intervention for biliary leaks after laparoscopic cholecystectomy: a multicenter review. Gastrointest Endosc 1998; 47: 261 266
}

\section{Corresponding author}

\section{G. Adler, M.D.}

Division of Gastroenterology

and Hepatology

University of Texas-Houston

Health Science Center

MSB 4.234

6431 Fannin

Houston, Texas 77030

USA

Fax: +1-713-500-6699

E-mail: douglas.adler@uth.tmc.edu 